\title{
Entrevista com Eduardo Peñuela
}

\section{Poética da Imagem}

\section{Resumo}

A temática da Poética da Imagem tem sido trabalhada de forma crescente nos dias de hoje. Na presente entrevista, Eduardo Peñuela Cañizal situa esse campo de pesquisa, apontando limites e perspectivas com que hoje ela é objeto de indagação, além de relacioná-la no contexto da comunicação contemporânea. Professor e pesquisador há longos anos no campo da semiótica da imagem, o entrevistado tem autoridade reconhecida na área, visualizada inclusive pela extensa produção a respeito, veiculada em livros e revistas do país e do exterior. Ex-diretor da Escola de Comunicações e Artes, da USP, acumulou larga experiência també na discussão da temática em encontros e congressos, nacionais e internacionais, realizados nesse campo de estudo.

NO- Como situar, hoje, o campo de estudo e pesquisa sobre poética da imagem?

EP-Em princípio, a poética, quanto aos seus fundamentos, é um termo cujo conteúdo, de um lado, se relaciona com a função estética, tal qual definida por Jakobson. Por outro lado, ela se insere na tradição dos estudos de retórica, revitalizados por Roland Barthes na década de 1970, que já em 1964, publicara, no número 4 da revista Communications, seu famoso ensaio Rhétorique de l'image. Em 1968, Gerard Genette, retomando manuais esquecidos de autores como Lamy, Du Marsais, Crevier, Domairon e Fontanier, entre outros, divulga, no número $11 \mathrm{At} \mathrm{Tel}$
Quel, periódico da vanguarda intelectual do momento, idéias defendendo a atualidade do estudo dos tropos em artigo intitulado La Rhétorique et l'espace du langage. Nesse contexto, um grupo de pesquisadores lança, em 1970, um livro que, ainda hoje, se configura fundamental. Refiro-me à Rhétorique Générale, de autoria de J.Dubois, F. Edeline, J.M. Klinkerberg, P. Minguet, F. Pire e H. Trinon. Traduzida em várias línguas, inclusive no português, esta obra parte do pressuposto de que é possível estabelecer princípios universais capazes de sistematizar a análise dos diversos processos metabólicos produmzidos pelas chamadas figuras de linguagem. Vale dizer, por conseguinte, que as metáforas, por exemplo, subordinam suas múltiplas modalidades constitutivas, seja qual for a cultura em que se realizam, a determinadas causas invariáveis. Nessa perspectiva, a poética se instaura como uma disciplina cujo principal objetivo consiste em apontar o invariável subjacente a qualquer fenômeno que represente uma ruptura dos parâmetros morfológicos, sintáticos e semânticos de um sistema de signos. Em suas raízes, o sistema privilegiado pela Poética foi, quase sempre, o sistema verbal, apesar de Jakobson advertir que os fenômenos poéticos podem ocorrer em qualquer sistema de signos. Nas últimas décadas do século passado, surgem vários trabalhos, principalmente publicados em revistas, centrados nos valores propriamente poéticos de mensagens visuais. Paradigmas dessa tendência são, por exemplo, os números que o
Eduardo Peñuela Cãñizal é professor e pesquisador, aposentado, junto à Escola de Comunicações e Artes da USP, Departamento de Cinema, Rádio e Televisão. 
periódico 11 Progresso Fotografico dedicou à manifestação dos tropos em mensagens fotográficas. Mas é com o aparecimento do Traité du Signe Visuel, livro lançado pelo Groupe $\mu$ em 1992, hoje traduzido em várias línguas, que os estudos sobre a poética do icônico e do plástico ganham consistência. $\mathrm{Na}$ atualidade, proliferam publicações dedicadas à poética, o que mostra a pujança deste domínio de estudos. Dentre elas, destaco a revista Visio, vinculada à Associação Internacional de Semiótica Visual. Neste periódico, o leitor poderá encontrar os resultados de pesquisas de ponta realizadas em vários países do mundo e, além disso, a diversidade de tendências que se entrecruzam, neste momento, no complexo território da poética: a manifestação estética nos objetos híbridos ou mestiços, a poesia de mensagens não-verbais dos mais diversos teores, os avanços tecnológicos utilizados na função de instrumentos forjadores de configurações expressivas originais e, portanto, geradoras de conteúdos insólitos, a plástica e a textura das imagens digitais enquanto traços materiais produtores de sentido, os processos de ruptura nas maneiras de contar, para citar tão somente alguns âmbitos de ocorrência. Pode-se dizer, enfim, que o campo da Poética congrega disciplinas de forte tradição humanística tais como a Filologia, a Estilística, a Estética, a Retórica, a Filosofia da Linguagem, a Lingüística, a Semiótica, a Lógica, Narratologia e a Iconografia, possibilitando uma integração aberta ao diálogo com outros universos do saber, entre os que certamente estão os da Psicanálise, da Antropologia e das Ciências ditas Cognitivas.

\section{NO- É possível relacionar esta definição moderna de poética à mais tradicional? EP-Boa parte da crítica de arte que hoje lemos em jornais de grande circulação utiliza o termo de maneira indiscrimi- nada. Fala-se sobre a poética de deter- minado autor, por exemplo, a poética de Regina Silveira, de Nelson Pereira dos Santos ou de Glauber Rocha. Isso é}

estilo. Eu me filio àquele tipo de pensamento em que se entende poética como a disciplina que estuda os pressupostos invariáveis de considerável conjunto de processos de ruptura ou alotopia, isto é, de fenômenos que alteram as formas expressivas e semânticas dos componentes de um sistema de signos qualquer. Os efeitos dessas transgressões se fazem sentir em unidades morfológicas ou sintáticas e, também, nos enunciados de uma frase ou de um relato. Num quadro de Picasso é freqüente encontrar contorções que transfiguram as formas ditas icônicas e num filme de Godard não será difícil constatar que a ordem de uma fábula convencional é desmantelada. Mas tais desvios, embora constituam características do estilo desses autores, estão subordinados, mesmo que pareça paradoxal, a regras que valem também para outros autores. A elipse, para citar um recurso poético que recai sobre o relato de um quadro, um filme ou um romance, não é apanágio deste ou daquele artista. Conseqüentemente, a elipse é uma figura poética que pode ser utilizada por qualquer criador para conferir ao relato que ele desenvolve uma determinada forma. Vale dizer, portanto, que esse procedimento poético não é propriedade particular, digamos, de Godard ou de Resnais. É, isso sim, um molde poético do qual pode se servir um cineasta ou um pintor. Dessa perspectiva, parece-me mais coerente falar da maneira como o artista manipula o molde e não que o artista possui uma poética particular. Os falantes de uma língua têm, sem dúvida, suas singularidades, mas isso não significa que cada um desses falantes invente uma língua própria. Se assim fosse, ninguém se entenderia. A metáfora, seja em Guimarães Rosa ou em Portinari, sempre será identificada como tal pela simples razão de que essa figura detém, independente de suas particularidades e graus de originalidade, as características estabelecidas pela poética em sua tarefa de classificar os tropos. Nesse sentido, o conceito moderno de poética se vincula ao pensamento aristotélico, principalmente 
quando se pensa que o filósofo grego perseguia os princípios universais subjacentes a qualquer processo poético. É suficiente prestar atenção no conceito de mimese para perceber esse propósito. Assim, por exemplo, Aristóteles trata de diferenciar as artes a partir dos objetos imitados e do modo de imitar esses objetos, procurando, com isso, invariáveis de valor universal. Outro tanto se pode dizer quanto às suas idéias a respeito da metáfora, entendida por ele como o resultado da translação de um nome alheio, do gênero à espécie ou da espécie ao gênero. A metáfora seria, pois, uma "voz peregrina" e, se numa obra predomina essa figura, a decorrência semântica será fatalmente o enigma. Também se sabe que sobre a ambigüidade, questão predominante na poética de nossos dias, Platão derramou muita tinta em seus famosos diálogos.

No Cratilo, por exemplo, discute em profundidade o problema da arbitrariedade dos signos, assunto extremamente relevante para o estudo da manifestação das figuras poéticas em sistemas não-verbais, tão manipulados na cultura contemporânea. Enfim, não se trata de traçar aqui um panorama diacrônico da evolução dos estudos retóricos e, por isso, creio que esses conceitos, retomados constantemente no transcorrer de muito séculos, permitem defender o pressuposto de que a poética de hoje mantém vínculos muito estreitos com a tradição. Prova evidente desses vínculos pode ser encontrada se cotejamos os conceitos de metáfora do Groupe $\mu$ com os de Aristóteles. A grande diferença radica numa crescente tentativa de precisão, de aperfeiçoar os moldes, esforço que se deixa sentir também se comparamos os conceitos de metáfora utilizados por Jakobson e Lacan com o modelo dessa figura construído pelos autores da Rhétorique Générale. Por outro lado, acredito, ainda, que, uma vez que em nossos dias os estudos de poética que se realizam a partir das mensagens visuais - cinema, fotografia, pintura, vídeo e todo tipo de configurações digitais - têm crescido consideravelmente e propiciado instrumentos de leitura bastante eficazes, a visita a alguns tratados clássicos destinados ao exercício de interpretar imagens depara surpresas extraordinárias. A esse respeito, julgo fascinantes os comentários de Filóstrato em seu livro Imagines. Suas recomendações, principalmente no atinente aos lugares em que se localiza a ambigüidade, são de uma atualidade impressionante. A famosa Iconologia de Cesare Ripa preserva ainda um insólito frescor e suas explicações nos fazem entender melhor o caráter argumentativo da metáfora, tese defendida pelo Groupe $\mu$ em trabalho que Jean-Marie Klinkerberg apresentou recentemente em Congresso celebrado na Universidad Autónoma de México. Acrescente-se a isso que algumas passagens de autores clássicos, caso específico do relato de Plínio em sua Historia Naturalis sobre a contenda dos pintores Zêuxis e Parrásios, merecem ser relidos, pois há neles problemas, o da mimese fundamentalmente, que a poética de nossos dias começa a equacionar de modo adequado, já que também é de interesse da poética a questão dos gêneros e, nesse já lendário episódio é freqüente que os historiadores da arte passem em branco, obcecados em encontrar as origens do gênero natureza morta, o fato, como conta Plínio, de os pássaros se aproximarem de um quadro para bicar os frutos que nele se representam. Evidentemente, essa proeza conseguida por Zêuxis não é tão sutil quanto à da cortina pintada por Parrásios, capaz, no caso, não só de enganar os pássaros, mas o próprio Zêuxis (se é que Zêuxis, em verdade, foi ludibriado, pois, em minha opinião, o famoso pintor grego fingiu deixar-se enganar para mostrar aos que julgavam o certame que ele possui um entendimento de arte em que a ambigüidade desempenhava um papel central).

\section{NO- O objeto da ambigüidade, tem sido} trabalhado na contemporaneidade?

EP-Qualquer tipo de imagem construída em nosso tempo possui, por força, uma dupla ambigüidade. Uma que se manifesta no texto propriamente dito e outra que se camufla nas relações que esse 
texto tem com outros textos de momentos culturais pertencentes a espaços e tempos muito diferentes. Enquadrar, de ângulos insólitos, um torso feminino, como fizeram alguns fotógrafos surrealistas, para gerar configurações ambíguas é, sem dúvida, um recurso que interessa vivamente a poética. De igual maneira, quando se descobre que a forma dos testículos do touro pintado por Picasso em seu Guernica mantém uma relação iconográfica com o to do alfabeto grego e que a testa desse mesmo touro disfarça um a em posição vertical, os enunciados da pintura colocam em evidência um processo de intertextualidade através do qual se infiltra no famoso mural a mensagem de que esse bombardeio da cidade basca era "o começo do fim". Também esse procedimento interessa à poética. Com os avanços tecnológicos, os recursos expressivos geradores de ambigüidade se multiplicaram de modo impressionante e, conseqüentemente, o conjunto dos objetos de estudo da poética hoje é maior do que nunca.

NO- Buñuel costumava citar a seguinte frase do filósofo catalão Eugênio D'Ors: "Tudo o que não é transição, é plágio". Na boca de Bû̃uel, essa parece uma frase muito conservadora. É claro que ambos a diziam ironicamente, mas é que esta frase implica o universo da ruptura, talvez a ruptura seja esta transição. $O$ que o senhor acha a respeito da ruptura?

EP-A ruptura, entendida como poética, é um mecanismo que sempre existiu. Desde que o homem passa a ter uma relação social por meio da linguagem, desde que o ato de fala pode ser visto como um ato social, a ruptura se implanta como possibilidade. Portanto, ela existe até nas culturas mais primitivas. A ruptura, tanto a que se dá no plano da expressão quanto a que ocorre no plano do conteúdo, é inerente a qualquer sistema de signos. Sem ela, a linguagem seria monótona e a poesia não existiria. Quanto à frase de D'Ors citada, Buñuel caberia dizer, antes de tudo, que ela é unamuniana, pois foi Unamuno quem, no contexto espanhol, defendia a tese de que qualquer inovação depende da tradição. Melhor ainda, a frase é quixotesca e não cabe dúvida quanto ao fato de que o cinema de Buñuel é quixotesco, poeticamente absurdo no sentido de que seu cinema lida com o realismo transcendido, traço da cultura hispânica que encontramos em Velázquez, em Cervantes, em Picasso e em Almodóvar. Do outro lado da "realidade" que nos circunda existem "lugares" onde a significação se esconde, é para esses "lugares" que a imaginação se dirige, procurando sempre o rumo de uma transcendência sem fronteiras. Nesse constante movimento de transição, os filmes de Buñuel mostram que é possível romper com a lógica do hábito, com as normas do costume e, sobretudo, com as miragens das aparências. Creio, pois, que a ruptura, nesse contexto da transição, representa o desmantelamento de uma isotopia, isto é, dos significados que por força da repetição se fossilizam, de modo que a ruptura, enquanto procedimento de abalar tais fossilizações, nada mais é do que um movimento alotópico ou seja, uma tentativa de fugir do "lugar comum" das coisas e descobrir nelas a existência de significados entranháveis. Por isso Buñuel condenava o neo-realismo do cinema italiano. Ele não se conformava com a idéia de que a imagem de um copo, por exemplo, teria de ser inevitavelmente a imagem de um copo com os significados que objeto possui na vida cotidiana das pessoas. $O$ cineasta espanhol tinha como lema transitar e ultrapassar sempre o lado visível das coisas. Em conferência que fez na Universidade Autônoma do México, o cineasta definiu o cinema como um texto semelhante aos textos oníricos, textos possuidores da capacidade extraordinária de fazer visível o que não se vê.

NO- O que é imagem? Não seria exatamente o estado da ambigüidade?

EP-A imagem é um texto. E eu defino um texto utilizando o pensamento dos cientistas da linguagem da chamada Escola de Tartu, da Rússia. Um texto é uma tessitura de signos com começo e 
fim. Então o poema é um texto, um filme hipertexto é fundamentalmente um é um texto, um quadro é um texto. Dentro sistema intertextual. Mas, em textos deste conceito, distingo duas literários, por exemplo, a intertexmodalidades textuais básicas: o texto tualidade é quase sempre uma alusão, homogêneo, feito apenas de um sistema ao passo que, nos textos eletrônicos ou de signos, e o heterogêneo, com vários sistemas de signos. Um quadro, uma fotografia, um filme. Não há nenhuma imagem que possa ser classificada como um texto homogêneo. É muito difícil achar um texto homogêneo. $\mathrm{O}$ único exemplo que me ocorre como texto homogêneo é o semáforo porque não se pode ficar diante do semáforo pensando que seu vermelho é bonito, porque essa cor não está ali para criar conotações. Os textos estéticos, artísticos, são todos heterogêneos. Posso dizer que, mesmo não sendo artística, uma imagem, pelo fato de constituir um texto heterogêneo, sempre será ambígua, admitindo, entretanto, que essa ambigüidade possui gradações. Colocado diante de uma imagem, o observador decodifica unicamente significados a partir dos códigos que lhe são familiares, mas isso não quer dizer que o observador, considerando a heterogeneidade do texto imagético, seja capaz de decifrar todos os códigos que se imbricam numa imagem e, em virtude dessas limitações, não me parece arriscado concordar com a idéia de que a imagem seja o estado da ambigüidade.

NO- Como relacionar o contexto atual de mídia eletrônica com o da recepçaõ, sobretudo virtual? A imagem, como texto, de começo meio e fim. Existe a poética da imagem virtual?

EP-Restrinjo-me a falar do hipertexto. Hoje vivemos submersos numa galáxia de textos e não é difícil ter acesso a imagens que giram em tomo de um mesmo tema. Mas uma das particularidades mais admirável do hipertexto é fazer com que sobre esse tema recaiam enxurradas de informação e, sobretudo, fazer com que o leitor viva a polissemia desse tema a partir do instante em que nele se concentram "vozes", no sentido que Bahktin atribui a esse termo, vindas de lugares remotos. Landow, em seu já clássico estudo sobre o hipertexto, destacava o princípio de que o nos hipertextos propriamente ditos, as alusões podem se explicitar e gerar ambigüidades a partir dos conflitos que os jogos entre implicitação e explicitação criam. Constatado isso, temos de admitir que os produtos engendrados pelas tecnologias mais recentes não só produzem imagens impregnadas de poesia, mas demarcam, também, um domínio propício às investigações da poética. Enfim, tanto no atinente ao dialógico quanto no que diz respeito ao hipertextual, a poética encontra campos novos em que pode testar seus instrumentos interpretativos.

NO- Como o senhor relaciona estes processos com o processo de recepção? E quanto à produção, como se dá a produção poética?

EP- Tudo o que disse até agora se relaciona, em boa parte, com a esfera da recepção, e também, com alguns aspectos da imanência de um texto. Pouco falei sobre a produção, embora tenha de admitir que a intertextualidade tem um forte compromisso com os códigos de emissão. Admitindo como consistente a premissa da transição, é evidente que a poética constitui, em certa medida, uma ferramenta útil para estudar aspectos de recepção, principalmente quando se trabalha com o pressuposto de que o destinatário da mensagem é também um sujeito da enunciação. Nesse sentido, por exemplo, se as figuras de linguagem possuem valores argumentativos, é evidente que, nesse caso, elas desempenham papel de relevância nos processos de recepção.

Quanto à produção poética, isso em qualquer época, se dá também pela ousadia e originalidade. Sem atentado aos códigos e sem o efeito de escândalo que eles produzem não há poesia. $\mathrm{E}$ entenda-se que não há poesia em nenhum tipo de texto, nem no cinema, nem nos poemas verbais, palavras, nem na fotografia, nem na pintura. Como Roland Barthes disse, inspirando-se em idéias 
de Valle-Inclán, dramaturgo e poeta espanhol que é relativamente bem conhecido no Brasil, a poesia nasce no instante em que o poeta é capaz de colocar juntas duas palavras que nunca estiveram juntas antes. Essa é a definição chave para Barthes e esse é, no fundo, o molde em que cabem todas as figuras de linguagem em termos da sua fabricação. Pensemos, por exemplo, no ponto de vista, tão importante para situar o espectador de um quadro ou de um filme, ou mesmo para construir um relato. Os grandes pintores obrigam o observador de uma obra à tarefa de encontra diferentes pontos de vista, ao trabalho de se deslocar diante do quadro para poder atingir aspectos das imagens representadas que só podem ser percebidos de acordo com um certo ponto de vista. Outro tanto ocorre com um relato.
NO- E aí está a ruptura?

EP-E aí está a ruptura, porque a ruptura também leva o leitor, no processo da recepção, a se deslocar de ponto de vista. Esse deslocamento é como se você regulasse uma lente que não está bem, você a ajeita e consegue ver melhor, ver mais. Também a ruptura provoca um deslocamento, uma saída do lugar comum do próprio receptor. Sempre tive como objetivo, na disciplina Poética da Imagem, que lecionava na ECA, fazer com que meus alunos, no final do curso, fizessem uma crítica. Se realmente se configurasse que, a partir do instante em que eles terminaram a disciplina, eles passassem a ver as coisas de alguma outra maneira, diferente daquela que tinham antes, a disciplina teria cumprido satisfatoriamente seus objetivos.

\section{Bibliografia do Entrevistado}

PEÑUELA CAÑIZAL, E, La Visualidad Sonora em Autoretratos de Frida Kahlo, São Paulo: CEPPI, 2002.

PEÑUELA CAÑIZAL, E, La Consagración Poética de Cartografias dei Gesto. México: Universidad Autónoma Metropolitana UAM, 2001.

PEÑUELA CAÑIZAL, E, Surrealismo: Rupturas expressivas. São Paulo: Atual, 1987.

PEÑUELA CAÑIZAL, E, O Mito e sua Expressão na Literatura Hispano- Americana. São Paulo: Duas Cidades, 1982.

PEÑUELA CAÑIZAL, E, Duas Leituras Semióticas. São Paulo: Perspectiva, 1977. v.1.

PEÑUELA CAÑIZAL, E, La Consagración del Instante. São Paulo: ICHSP/USP, 1968.

PEÑUEla CAÑIZAL, E, A poesia de Fernando Pessoa. São José do Rio Preto/ SP: ICH, 1964. 